\title{
The Research on Road Congestion Of Pre-diversion Method
}

\author{
GAO Zhong-wen \\ School of Automation \\ Harbin University of Science and Technology \\ Harbin, China \\ xygaozw@126.com
}

\author{
DING Ling \\ School of Automation \\ Harbin University of Science and Technology \\ Harbin, China \\ dingdling@163.com
}

\author{
SONG Wei-wei \\ Information Engineering \\ Heilongjiang institute of information technology \\ Harbin, China \\ xygaozw@126.com
}

\begin{abstract}
As Chinese economy is thriving rapidly, traffic congestion in urban areas is often the outcome of successful urban economic development, employment and housing. Urban traffic congestion must be understood in the wider context of city dynamics and agglomeration benefits.This study focused on the path selection and optimization of the prediversion road congestion problem,theoretical analysis and simulation of the traffic pre-diversion,analysis the comparative data between diversion road network and basic road network.Determined consitute and quantitative methods of the diversion cost.Evaluation of diversion benefit solutions by the microtraffic simulation software VISSIM which demonstrate its effectiveness.
\end{abstract}

Keywords-traffic congestion;pre-diversion model;microscopic traffic simulation;road network

\section{INTRODUCTION}

The traffic pre-diversion means in the case of the road network conditions exist other optional path,bring part or all of the traffic upcoming flow transferred to the other paths to reduce the serious congestion of local roads when predicted a road traffic congestion state. In recent years, it carry out many research on diversion theory analysis at home and abroad.e.g. Rigid and flexible combination of traffic diversion method[1] by SONG Xuewen; Application of Macro and Microscopic Simulations for the Traffic Planning of Urban Highway Reconstruction[2] by Eul-Bum Lee; He Hanhui and other people in terms of travel time, fuel consumption, along speed traffic simulation application research, using American TSIS simulation software on a highway diversion program[3]; Regional traffic diversion road network optimization[4] by GALLO M .Yan Youqi and others on the basis of the shortest path traffic assignment method, introduced for the shortest road maximum flow analysis techniques, the shortest road maximum flow calculation method of traffic assignment[5] etc.

Heilongjiang Provincial Department of Education planning issues (Topic No.GZC1211079).
Therefore, path optimization is an effective way to solve the problem of traffic congestion.In this paper, proposed a method of quantitative analysis based on the choice of the path.

\section{TOTAL TIME COST MODEL OF PRE-DIVERSION}

Assuming the road network in Figure l, estimated the sections between the node $A$ to node $B(A, B)$ is going to congestion on point $\mathrm{O}$,point $\mathrm{A}$ is the diversion starting point, the target flow $\mathrm{R}$ through other path from point $\mathrm{A}$ to reach point $\mathrm{B}$.

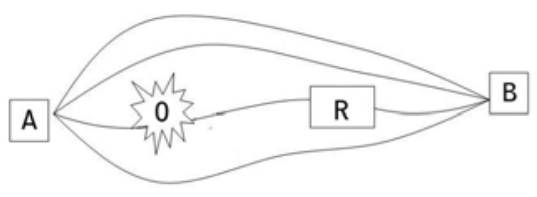

Figure 1. The road network occurs congestion

\section{A. Calculation of the pre-diversion flow}

We use $N_{r}$ represent the diversion critical capacity of the sections r, $\hat{N}_{r}(t+\Delta t)$ represent the cars number on sections $r$ at the time of $(t+\Delta t)$ :

$$
\begin{gathered}
N_{r}=Q_{r}^{\prime}\left(l_{r} / v_{r}\right) \\
\hat{N}_{r}(t+\Delta t)=\hat{Q}_{r}(t+\Delta t)\left[l_{r} / \hat{v}_{r}(t+\Delta t)\right]
\end{gathered}
$$

$Q$ represent the diversion critical capacity of sections $r$;

$\hat{Q}_{r}(t+\Delta t)$ represent the traffic of sections $\mathrm{r}$ at the time of $(t+\Delta t) ; N_{r}$ represent diversion critical capacity of the sections $\mathrm{r} ; \hat{N}_{r}(t+\Delta t)$ represent the cars number on sections $r$ at the time of $(t+\Delta t) ; L_{r}$ represent the length of the sections $r ; v_{r}$ represent the diversion critical speed of the 
sections $\mathrm{r} ; \hat{v}_{r}(t+\Delta t)$ represent the average vehicle traveling speed on sections $r$ at the time of $(t+\Delta t)$.

The sections $r$ would not occurred congestion when the cars number met the conditions of $\hat{N}_{r}(t+\Delta t) \leq N_{r}$. When met the conditions of $\hat{N}_{r}(t+\Delta t)>N_{r}$, the number of diverted vehicles is $\Delta N_{r}(t+\Delta t)$. As in formula (1-3):

$$
\Delta N_{r}(t+\Delta t)=\hat{N}_{r}(t+\Delta t)-N_{\mathrm{r}}
$$

We use $\Delta N_{r_{n}}(t+\Delta t)$ represent the vehicles number of inflow path $r_{n}$ in target stream,compare the size of $\Delta N_{i_{n}}(t+\Delta t)$ and $r_{n}$ with the remaining flow $\Delta q_{r_{n}}(t+\Delta t)$, if $\Delta N_{r_{n}}(t+\Delta t) \leq \Delta q_{r_{n}}(t+\Delta t), r_{n}$ represent diversion path;if $\quad \Delta N_{r_{n}}(t+\Delta t)>\Delta q_{\mathrm{r}_{\mathrm{n}}}(t+\Delta t) \quad$ diversion path is $\Delta N_{r_{n}}(t+\Delta t) / \Delta q_{r_{n}}(t+\Delta t)=h$.In this paper assuming that diversion capacity of each deversion path is equal,,h rounded up.

\section{B. The calculation of the total time cost of the pre- diversion efficiency}

Impedance functions of the United States Federal Highway Administration:

$$
t=t_{0}\left[1+\alpha\left(\frac{\mathrm{q}}{\mathrm{C}}\right)^{\beta}\right]
$$

Then $\mathrm{t}$ represent travel time; $t_{0}$ represent free travel time; $q$ represent traffic flow;c represent link capacity; Parameter $\alpha$ and $\beta$.If $t_{0}=c_{1}, t_{0} \alpha / \mathrm{c}^{\beta}=c_{2}$, the time cost function of road $\mathrm{R}$ is:

$$
t=c_{1}+c_{2} q^{\beta}
$$

Time totle cost before diversion is the sum of $h$ diversion roads and road $\mathrm{R}$ :

$$
T=\sum_{n=1}^{h} l_{n}\left(c_{1 \mathrm{n}}+c_{2 \mathrm{n}} q^{\beta}\right)+\left(c_{1 \mathrm{k}}+c_{2 \mathrm{k}} q^{\beta}\right)
$$

If we guide traffic diversion, part of the flow of road $\mathrm{R}$ will distributed to other roads,if represent diversion flow is $\triangle \mathrm{q}$, the total flow Increasing is $\triangle \mathrm{q}$ on other roads .In this paper assuming that diversion capacity of each deversion path is equal,the number of the diversion path is h,the totle time cost after diversion is

$$
T^{\prime}=\sum_{n=1}^{h} l_{n}\left[c_{1 n}+c_{2 n}\left(q+\frac{\Delta q}{\mathrm{~h}}\right)^{\beta}\right]+\left[c_{1 \mathrm{k}}^{\prime}+c_{2 \mathrm{k}}^{\prime}(q-\Delta q)^{\beta}\right]
$$

The formula of total time cost of the diversion effective:

$$
T-T^{\prime}=\sum_{n=1}^{h} l_{n}\left[c_{2 \mathrm{n}}\left(q+\frac{\Delta q}{\mathrm{~h}}\right)^{\beta}-c_{2 \mathrm{n}} q^{\beta}\right]+c_{2 \mathrm{k}}\left[(q-\Delta q)^{\beta}-q^{\beta}\right]
$$

\section{ANALYSIS OF SIMULATION RESULTS}

Use of microscopic traffic simulation software VISSIM , Examples of road network in Figure, the main road is a two-way eight-lane, the roadside on each side is a two-way lane roads, the Analog numbered sections of EF lane will occur congestion at this time's traffic flow that it is necessary to conduct a traffic pre-diversion.As can be seen from Figure 2, in the Preparation of the sections where the accident occurrence have two nearer exit, and we can guiding the vehicle to be diverted respectively from the points $\mathrm{B}$ and $\mathrm{D}$ in advance.Figure 2 is a diagram of the simulation results of the congested road traffic conditions.

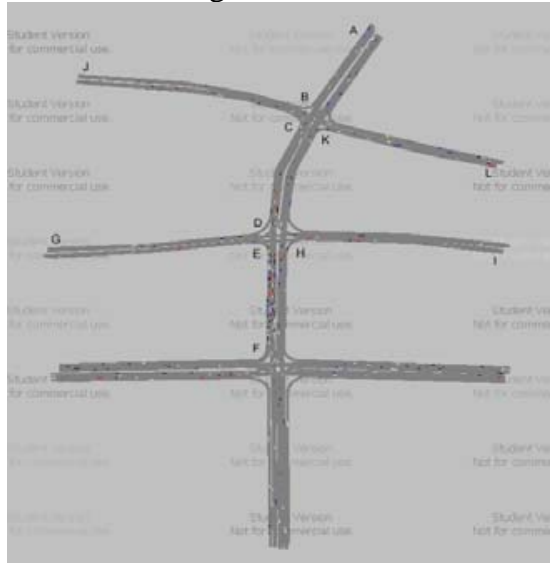

Figure 2. Traffic simulation of the congestion road network

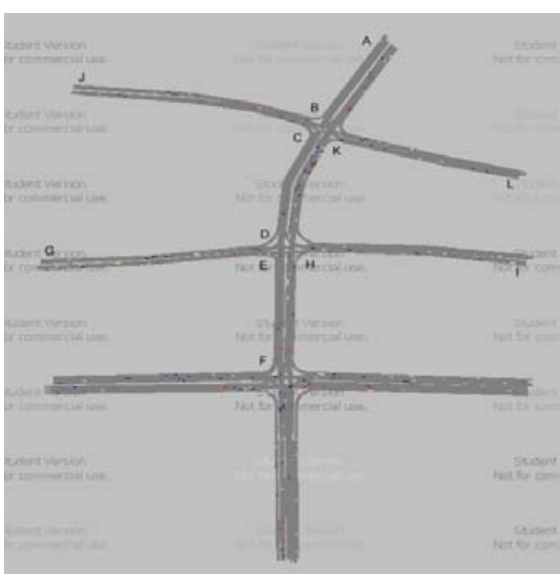

Figure 3. Traffic simulation of the pre-diversion road network

We can see from Figure 3,the speed of the vehicle greatly increase because of improve the vehicles' traveling programs on the roads. The queues of various sections have been eased and the running condition of the vehicle on the section has been improved significantly.

\section{EVALUATE IMPROVEMENT PLAN OF THE PRE- DIVERSION}

VISSIM is a micro-simulation modeling tools based on the time interval and the driving behavior of the driver - 
vehicle - unit as the basic entity.It can be analyzed under various traffic conditions, such as lane set, traffic composition, traffic signals, bus stops, urban transport and public transport running condition.It's an effective tool for the evaluation of traffic engineering and urban planning programs.

\section{A. Comparison of the vehicle travel time}

The average travel time (including parking or waiting time) is the time interval between the starting point of the vehicle through the detection zone to the ending point. The road congestion level can be evaluated by the journey time, size, location and reasons to determined the countermeasures for alleviate congestion. Patency of the vehicle through the interval can be know by the travel time ,it can provided travel time based on road network for traffic assignment.As shown in Table 1 and Table 2.

TABLE I. VEHICLE TRAVEL TIME OF THE PRE-DIVERSION

\begin{tabular}{|l|l|l|}
\hline $\begin{array}{c}\text { Sections } \\
\text { Numbers }\end{array}$ & $\begin{array}{c}\text { Travel } \\
\text { Times(s) }\end{array}$ & $\begin{array}{c}\text { vehicles } \\
\text { number }\end{array}$ \\
\hline AB & 13.0 & 53 \\
\hline CD & 15.6 & 191 \\
\hline EF & 28.3 & 95 \\
\hline DG & 24.1 & 122 \\
\hline HI & 23.5 & 80 \\
\hline BJ & 26.1 & 130 \\
\hline KL & 19.9 & 68 \\
\hline
\end{tabular}

TABLE II. VEHICLE TRAVEL TIME AFTER DIVERSION

\begin{tabular}{|l|l|l|}
\hline $\begin{array}{c}\text { Sections } \\
\text { Numbers }\end{array}$ & $\begin{array}{c}\text { Travel } \\
\text { Times(s/s) }\end{array}$ & $\begin{array}{c}\text { vehicles } \\
\text { number }\end{array}$ \\
\hline AB & 12.7 & 25 \\
\hline CD & 13.3 & 94 \\
\hline EF & 15.8 & 99 \\
\hline DG & 23.8 & 134 \\
\hline HI & 24.0 & 124 \\
\hline BJ & 26.2 & 138 \\
\hline KL & 20.1 & 68 \\
\hline
\end{tabular}

\section{B. Link evaluation comparison}

The evaluate of the sections can be provided based on the road region rather than a simulation result based on the vehicle.Evaluation parameters including vehicle density, the relative loss of time, average speed, traffic etc. As shown in Table 3 and Table 4.

TABLE III. SECTIONS EVALUATION OF THE PRE-DIVERSION

\begin{tabular}{|l|l|l|l|l|}
\hline $\begin{array}{c}\text { Section } \\
\mathbf{s} \\
\text { Numbe } \\
\text { rs }\end{array}$ & $\begin{array}{c}\text { Vehiclede } \\
\text { nsity } \\
\text { [car/km] }\end{array}$ & $\begin{array}{c}\text { Relative } \\
\text { loss of } \\
\text { time[s] }\end{array}$ & $\begin{array}{c}\text { Average } \\
\text { speed } \\
\text { [km/h] }\end{array}$ & $\begin{array}{c}\text { volume[ } \\
\text { vehicles / } \\
\text { hour] }\end{array}$ \\
\hline AB & 4.62 & 0.14 & 44.25 & 203.56 \\
\hline CD & 9.33 & 0.25 & 38.42 & 360.41 \\
\hline EF & 27.76 & 0.59 & 21.73 & 517.11 \\
\hline DG & 6.72 & 0.01 & 52.72 & 352.92 \\
\hline HI & 11.80 & 0.01 & 52.41 & 615.46 \\
\hline BJ & 7.89 & 0.00 & 50.56 & 396.97 \\
\hline KL & 14.09 & 0.01 & 50.30 & 706.91 \\
\hline
\end{tabular}

TABLE IV. SECTIONS EVALUATION AFTER THE DIVERSION

\begin{tabular}{|l|l|l|l|l|}
\hline $\begin{array}{c}\text { Sections } \\
\text { Numbers }\end{array}$ & $\begin{array}{c}\text { Vehicled } \\
\text { ensity } \\
\text { [car/km] }\end{array}$ & $\begin{array}{c}\text { Relative } \\
\text { loss of } \\
\text { time[s/s] }\end{array}$ & $\begin{array}{c}\text { Average } \\
\text { speed } \\
\text { [km/h] }\end{array}$ & $\begin{array}{c}\text { volume[v } \\
\text { ehicles / } \\
\text { hour] }\end{array}$ \\
\hline AB & 2.20 & 0.07 & 47.62 & 106.11 \\
\hline CD & 3.84 & 0.14 & 44.88 & 178.21 \\
\hline EF & 15.46 & 0.20 & 40.98 & 626.57 \\
\hline DG & 8.35 & 0.01 & 50.97 & 425.95 \\
\hline HI & 12.10 & 0.01 & 52.16 & 620.73 \\
\hline BJ & 9.21 & 0.00 & 49.71 & 458.37 \\
\hline KL & 15.88 & 0.02 & 50.53 & 802.76 \\
\hline
\end{tabular}

\section{Comparison between Road Network Performance}

\section{Evaluation}

The road network performance evaluation can calculate the parameters of the entire road network throughout the simulation. Shown in Table 5.

From the above analysis, the travel time of the prediversion program、 average parking delays index are lower than non-diversion program, the average speed of the vehicle and traffic quantity are increased.We select comprehensive evaluation such as average speed in section 、 average parking delay times and traffic identified as congested state , determine every moment of the sections traffic state accurately.

\section{TABLE V. CONSTRAST DATA OF THE DIVERSION}

\begin{tabular}{|l|l|l|}
\hline \multicolumn{1}{|c|}{ Parameter } & \multicolumn{1}{|c|}{$\begin{array}{c}\text { Non- } \\
\text { diversion }\end{array}$} & \multicolumn{1}{c|}{$\begin{array}{c}\text { after } \\
\text { diversion }\end{array}$} \\
\hline $\begin{array}{l}\text { Average delay time } \\
\text { [s] }\end{array}$ & 8.347 & 5.131 \\
\hline Stopped delay [s] & 0.244 & 0.173 \\
\hline $\begin{array}{l}\text { Average speed [km } \\
\text { /h] }\end{array}$ & 43.384 & 46.015 \\
\hline $\begin{array}{l}\text { Total delay time [h] } \\
\text { Total traveling } \\
\text { distance [km] }\end{array}$ & 1401.1952 & 1373.838 \\
\hline $\begin{array}{l}\text { Total parking delays } \\
{[\mathrm{h}]}\end{array}$ & 0.551 & 0.355 \\
\hline Total travel time [h] & 32.297 & 29.856 \\
\hline
\end{tabular}

\section{CONCLUSION}

VISSIM Simulation results show that: calculating the pre-diversion traffic can effectively ease traffic congestion.Effectively induced traffic flow can be achieved through the established model,optimal path selection for travelers,the effects of travel groups time to achieve the best.Because we are not consider the intersection of time delay, appropriate amendments should be based on the actual road conditions in the practical application.

\section{REFERENCES}

[1] SONG Xuewen, ZHANG Peilin,LIU Tiexin.Research on the technology of traffic diversion for expansion engineering of expressways [J].Highways \& Automotive Applications, 2008( 3) : 45-47.

[2] LEE E B,KIM C,HARVEY J T.Application of Macroand Microscopic Simulations for the Traffic Planning of Urban 
Highway Reconstruction[C/CD]//TRB 2005 Annual Meeting.Washington D.C.: TRB,2005.

[3] HE Hanhui,LI Jia, ZHU Jianhe, etal. Anapplication study of computer simulation in traffic diversion plans[J].Central South Highway Engineering , 2007, 32( 2) : 99-102.

[4] R. Nicole, GALLO M,ACIERNO L,MONTELLA B.A Metaheuristic Approach for Solving the Urban Network Design Problem[J].European Journal of Operational Research,2010,201: 144-157.

[5] YAN Youqi, OUYANG Jianxiang . Traffic volume assignment method with maximum flow of minimum distance[J]. China Journal of Highway and Transport, 2005, 18(4) : 91-95.
[6] XIAO Hua.Wuhan urban road traffic congestion problems and countermeasures. Wuhan University of Technology,2006

[7] TAN Xiaojie.Based on the knowledge of the trafficcongestion to dredge decision method and system research[D].Southeast University,2005

[8] SI Bingfeng,ZHANG Haozhi,GAO Ziyou. Improved Dial algorithm solving Logit random network assignment[J].China Journal of Highway,2009

[9] CHENG Lin,etal.Intersection Diversion rate calculation method based on network equilibrium[J].Southwest Jiaotong University,2008

[10] PTV.VISSIM 5.20 USER MANUAI[Z].Germany:Planung Transport Verkehr AG,2009:407-458. 